\title{
Modified iPad for treatment of amblyopia: a preliminary study
}

Tomoya Handa, $\mathrm{CO}, \mathrm{PhD},{ }^{\mathrm{a}}$ Hitoshi Ishikawa, $\mathrm{MD}, \mathrm{PhD},{ }^{\mathrm{a}}$ Nobuyuki Shoji, $\mathrm{MD}, \mathrm{PhD},{ }^{\mathrm{a}}$ Tetsuya Ikeda, MD, ${ }^{\mathrm{b}}$ Satoru Totuka, CO, ${ }^{\mathrm{b}}$ Toshiaki Goseki, MD, PhD, ${ }^{\mathrm{b}}$ Kimiya Shimizu, MD, PhD ${ }^{\mathrm{b}}$

Author affiliations: ${ }^{a}$ Department of Rehabilitation, Orthoptics and Visual Science Course, School of Allied Health Sciences, Kitasato University, Sagamihara, Japan; ${ }^{b}$ Department of Ophthalmology, School of Medicine, Kitasato University, Sagamihara, Japan

Submitted March 16, 2015.

Revision accepted August 12, 2015.

Correspondence: Tomoya Handa, CO, PhD, Department of Rehabilitation, Orthoptics and Visual Science Course, School of Allied Health Sciences, Kitasato University, 1-15-1 Kitasato, Minami-ku, Sagamihara 252-0373, Japan (email: thanda@kitasato-u.ac.jp).

This study was supported by a grant from the Center for Revitalization Promotion Japan Science and Technology Agency (A-STEP) No. H25 Sen II- 566 (www.jst.go.jp). The funders had no role in study design, data collection and analysis, decision to publish, or preparation of the manuscript.

\section{Word count: 1,061}

(C) 2015. This manuscript version is made available under the Elsevier user license http://www.elsevier.com/open-access/userlicense/1.0/ 
We report the results of a new amblyopia treatment device used in 7 children with anisometropic amblyopia. The Occlu-pad was created by removing the polarizing film layer from the liquid crystal display screen of an iPad Air (Apple Inc, Cupertino, CA). Patients were asked to wear special glasses that contained a polarizing filter for their amblyopic eye and a light reduction filter for their normal eye and instructed to play an amblyopia training game displayed only to the amblyopic eye. In 5 patients corrected distance visual acuities in the amblyopic eyes improved after 2 months' treatment on average by 0.38 units of the logarithm of the minimum angle of resolution. Occlusion therapy ${ }^{1-3}$ is the primary treatment for amblyopia, but many children find the patching regimen difficult. This leads to concerns about treatment compliance. ${ }^{4,5}$ Moreover, occlusion therapy risks side effects such as skin irritation, deprivation amblyopia, and psychological issues associated with the inhibition of binocular function. We modified an iPad Air (Apple Inc, Cupertino, CA) to create a new amblyopia treatment device, the Occlu-pad (Yaguchi Electric Co Ltd, Ishinomaki, Japan) that displays images that can be seen by amblyopic eyes with polarized glasses. The purpose of this study was to test the Occlu-pad in children with anisometropic amblyopia.

\section{Materials and Methods}

This study conformed to the tenets of the Declaration of Helsinki and was approved by the Kitasato University Human Sciences Ethics Committee. A total of 7 children (3-7 years of age) with anisometropic amblyopia were treated using the Occlu-pad. The children and parents 
selected the amblyopia treatment using the Occlu-pad (Table 1). All patients had exophoria of $<10^{\Delta}$ by prism and cover testing at $30 \mathrm{~cm}$ and $5 \mathrm{~m}$. In addition to full refractive correction, all patients also underwent first amblyopia therapy with either the Occlu-pad or the Occlu-pad in addition to occlusion therapy for 3 hours daily.

The Occlu-pad was created by,removing only the polarizing film layer from the liquid crystal display (LCD) screen of an iPad Air (Figure 1E), making the LCD screen visible only with the aid of polarizing glasses; otherwise, the screen seems only to show a white backlight (Figure 1B). By designing the polarizing filter to exactly match the device polarization, information could only be perceived by a human eye. Enrolled patients were instructed to wear glasses containing a polarizing filter for their amblyopic eye and a light reduction filter for their normal eye, having the same transmittance as the polarizing filter, while playing an amblyopia training game loaded on the device (Figure $1 \mathrm{~A}$ ) for 1 hour daily. The treatment period was 4 weeks.

During the "catch-the-ants" game, patients viewed the screen with both eyes open. The "ants" were displayed only to the amblyopic eye (Figure 1C). To play the game, patients must drag the ants to an insect cage (Figure 1D). Patients had unimpeded binocular vision through the glasses, and thus their peripheral fusion was not hindered. To confirm treatment compliance, dates and times that patients played the training game were automatically logged by the device. To ensure continued interest, if patients tired of the game, they were allowed to play Web games or watch videos on Occlu-pad for the remainder of the treatment session. 


\section{Results}

The monthly training times that were automatically stored in the device in order to confirm treatment compliance were as follows: child 1, $960 \min$ (21 days); child 2, $680 \mathrm{~min}$ (26 days); child 4, 240 min (12 days); child 5, 290 min (10 days). Child 3 did not log any hours of playing the training game but, according to the parental accounts mother, did play the Web Game on the Occlu-pad every day; children 6 and 7 stopped using the Occlu-pad after their initial evaluation/training period. Children 4, 5, 6, and 7 all performed (additional) occlusion treatment (3 hours daily), almost every day for the treatment period.

Among the 5 patients who underwent Occlu-pad training, the corrected distance visual acuities in the amblyopic eyes (logarithm of the minimum angle of resolution [logMAR] values) at baseline and at 2 months' follow-up were as follows: child 1, 0.3 and -0.08 ; child 2, 0.22 and 0; child 3, 1.4 and 0.7; child 4, 0.4 and 0 ; and child 5, 0.15 and -0.08 . In all 5 patients the visual acuity improved in the patient's amblyopic eyes (Figure 2). In the 2 patients who stopped using the Occlu-pad after their initial evaluation/training period, corrected distance visual acuities in the amblyopic eyes (logMAR values) at baseline and 2 months were 0.4 and 0.3 in child 6 and 0.22 and 0.3 in child 7 , indicating no improvement visual acuity in these patients' amblyopic eyes (Figure 2).

\section{Discussion}

Childhood amblyopia has a reported prevalence of $1 \%$ to $5 \% .{ }^{6}$ When treating anisometropic amblyopia, improvement of the visual acuity of the amblyopic eye can often be attained through 
spectacle use only. In the present study, we used glasses with full refractive correction along with the Occlu-pad to treat children with anisometropic amblyopia. A clear improvement was noted in the visual acuity of the amblyopic eyes of children who performed treatment on the Occlu-pad for at least the minimum number of hours requested ( 3 patients using Occlu-pad training alone and 2 using the Occlu-pad with occlusion therapy for 3 hours daily). To play the game, use the Internet, or watch videos on the Occlu-pad, children had to wear the glasses with the polarizing filter and, therefore, we suggest that child used their amblyopic eyes positively while using the Occlu-pad. An additional benefit of the Occlu-pad is that treatment compliance can be easily monitored because the device automatically stores the dates and the times that the patient played the amblyopia training game. 


\section{References}

1. Awan M, Proudlock FA, Gottlob I. A randomized controlled trial of unilateral strabismic and mixed amblyopia using occlusion dose monitors to record compliance. Invest Ophthalmol Vis Sci 2005;46:1435-9.

2. Stewart CE, Stephens DA, Fielder AR, Moseley MJ; MOTAS Cooperative. Modeling dose-response in amblyopia: toward a child-specific treatment plan. Invest Ophthalmol Vis Sci 2007; 48:2589-94.

3. Simons K. Amblyopia characterization, treatment, and prophylaxis. Surv Ophthalmol $2005 ; 50: 123-166$.

4. Wallace MP, Stewart CE, Moseley MJ, Stephens DA Fielder AR; Monitored Occlusion Treatment Amblyopia Study (MOTAS) Cooperatives; Randomized Occlusion Treatment Amblyopia Study (ROTAS) Cooperatives. Compliance with occlusion therapy for childhood amblyopia. Invest Ophthalmol Vis Sci 2013; 54: 6158-66.

5. Carlton J. Kaltenthaler E. Amblyopia and quality of life: a systematic review. Eye 2011;25:403-13.

6. Attebo K, Mitchell P, Cumming R, Smith W, Jolly N, Sparkes R. Prevalence and causes of amblyopia in an adult population. Ophthalmology 1998;105:154-9. 


\section{Legends}

FIG 1. The Occlu-pad, a binocular open-view amblyopia treatment device. A, Home-based treatment using the Occlu-pad. B, White screen displaying to the unaffected eye. C, "Ants" displying to the amblyopic eye. D, Game play testing hand-eye coordination, with patients touching and dragging on-screen targets (ants) into the "insect cage." E, The Occlu-pad was made by removing only the polarizing film layer from the liquid crystal display (LCD) screen of an iPad Air. The special glasses designed for viewing the device were made with a light reduction filter for the normal eye and a circular polarizing lens for the amblyopic eye that contained a $\lambda / 4$ wave retarder and linear polarizing filter. The amblyopic eye can perceive the video information because the right polarizing filter matches the output of the LCD screen; however, the normal eye can only perceive the white backlight, because the light reduction filter does not match the screen output.

FIG 2. Progress during the 2-month amblyopia treatment period. 
Table 1. Patient characteristics and treatment details

\begin{tabular}{|c|c|c|c|c|c|c|c|}
\hline Characteristic & Child 1 & Child 2 & Child 3 & Child 4 & Child 5 & Child 6 & Child 7 \\
\hline $\begin{array}{l}\text { Age at start of } \\
\text { treatment }\end{array}$ & 5 yrs 10 mos & \multicolumn{2}{|c|}{6 yrs 8 mos 3 yrs 9 mos } & \multicolumn{4}{|c|}{4 yrs 3 mos 3 yrs 7 mos 4 yrs 2 mos 7 yrs 5 mos } \\
\hline Sex & $F$ & $F$ & M & $M$ & $M$ & $\mathrm{~F}$ & $\mathrm{~F}$ \\
\hline Amblyopic eye ${ }^{a}$ & $\mathrm{~L}$ & $\mathrm{~L}$ & $\mathrm{~L}$ & L & L & $\mathrm{R}$ & L \\
\hline $\begin{array}{cc}\text { Refraction } & \mathrm{R} \\
\text { (SE), D } & \mathrm{L}\end{array}$ & $\begin{array}{l}\mathrm{R}: 0.00 \\
+3.00\end{array}$ & $\begin{array}{l}+2.25 \\
+4.75\end{array}$ & $\begin{array}{l}+2.50 \\
+6.12\end{array}$ & $\begin{array}{l}+1.62 \\
+4.62\end{array}$ & $\begin{array}{l}+3.25 \\
+5.87\end{array}$ & $\begin{array}{l}+6.50 \\
+2.00\end{array}$ & $\begin{array}{r}+4.00 \\
+10.0\end{array}$ \\
\hline $\begin{array}{l}\text { Time with } \\
\text { glasses before } \\
\text { treatment }\end{array}$ & $\begin{array}{l}\text { At same time } \\
\text { as treatment }\end{array}$ & 3 mos & $1 \mathrm{mo}$ & 3 mos & $3 \mathrm{mos}$ & 3 mos & $3 \mathrm{mos}$ \\
\hline Treatment(s) & Occlu-pad & Occlu-pad & Occlu-pad & $\begin{array}{l}\text { Occlu-pad } \\
+ \text { occl }^{\mathrm{b}}\end{array}$ & $\begin{array}{l}\text { Occlu-pad } \\
+ \text { occl }^{\mathrm{b}}\end{array}$ & $\mathrm{Occl}^{\mathrm{b}, \mathrm{c}}$ & $\mathrm{Occl}^{\mathrm{b}, \mathrm{c}}$ \\
\hline \multicolumn{8}{|l|}{ BCVA, logMAR } \\
\hline At outcome ${ }_{L}^{R}$ & $\begin{array}{l}-0.08 \\
0.3\end{array}$ & $\begin{array}{l}0 \\
0.22\end{array}$ & $\begin{array}{l}0.15 \\
1.4\end{array}$ & $\begin{array}{l}0 \\
0.52\end{array}$ & $\begin{array}{r}-0.08 \\
0.52\end{array}$ & $\begin{array}{c}1 \\
-0.08\end{array}$ & $\begin{array}{l}-0.08 \\
0.3\end{array}$ \\
\hline $\begin{array}{l}\text { At start } R \\
\text { treatment } L \\
\text { After } 2 \text { mos } R \\
\text { treatment } L\end{array}$ & $\begin{array}{l}-0.08 \\
0.3 \\
-0.08 \\
-0.08\end{array}$ & $\begin{array}{l}0 \\
0.22 \\
-0.08 \\
0\end{array}$ & $\begin{array}{l}0.15 \\
1.4 \\
0 \\
0.7\end{array}$ & $\begin{array}{l}0 \\
0.4 \\
-0.08 \\
0\end{array}$ & $\begin{array}{r}-0.08 \\
0.15 \\
-0.08 \\
-0.08\end{array}$ & $\begin{array}{l}0.4 \\
-0.08 \\
0.3 \\
0\end{array}$ & $\begin{array}{r}-0.08 \\
0.22 \\
-0.08 \\
0.3\end{array}$ \\
\hline
\end{tabular}

$B C V A$, best-corrected visual acuity; $D$, diopter; $L$, left eye; LogMAR, logarithm of the minimum angle of resolution; Occl, occlusion; $R$, right eye; $S E$, spherical equivalent.

${ }^{a}$ All anisometropic.

${ }^{b}$ Occlusion 3 hours daily.

${ }^{\mathrm{C} O c c l u-p a d}$ not used. 

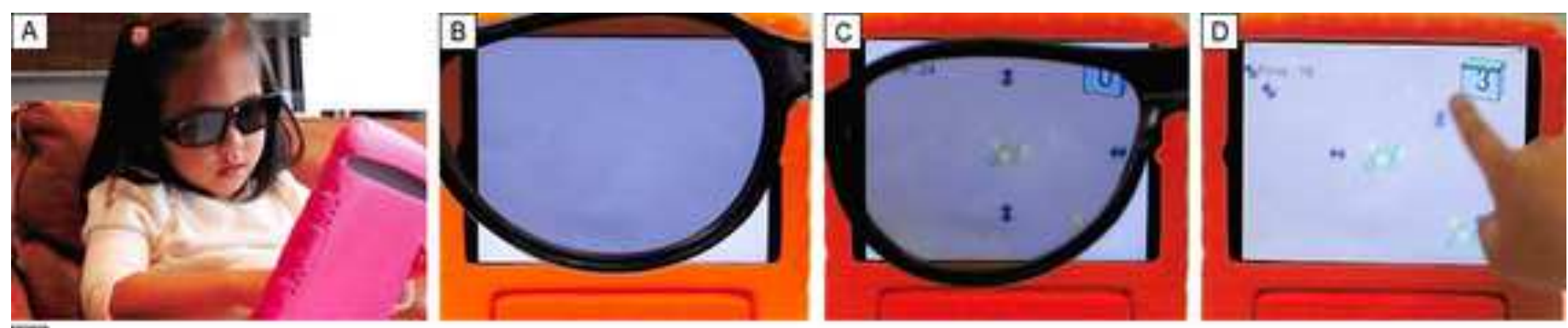

E

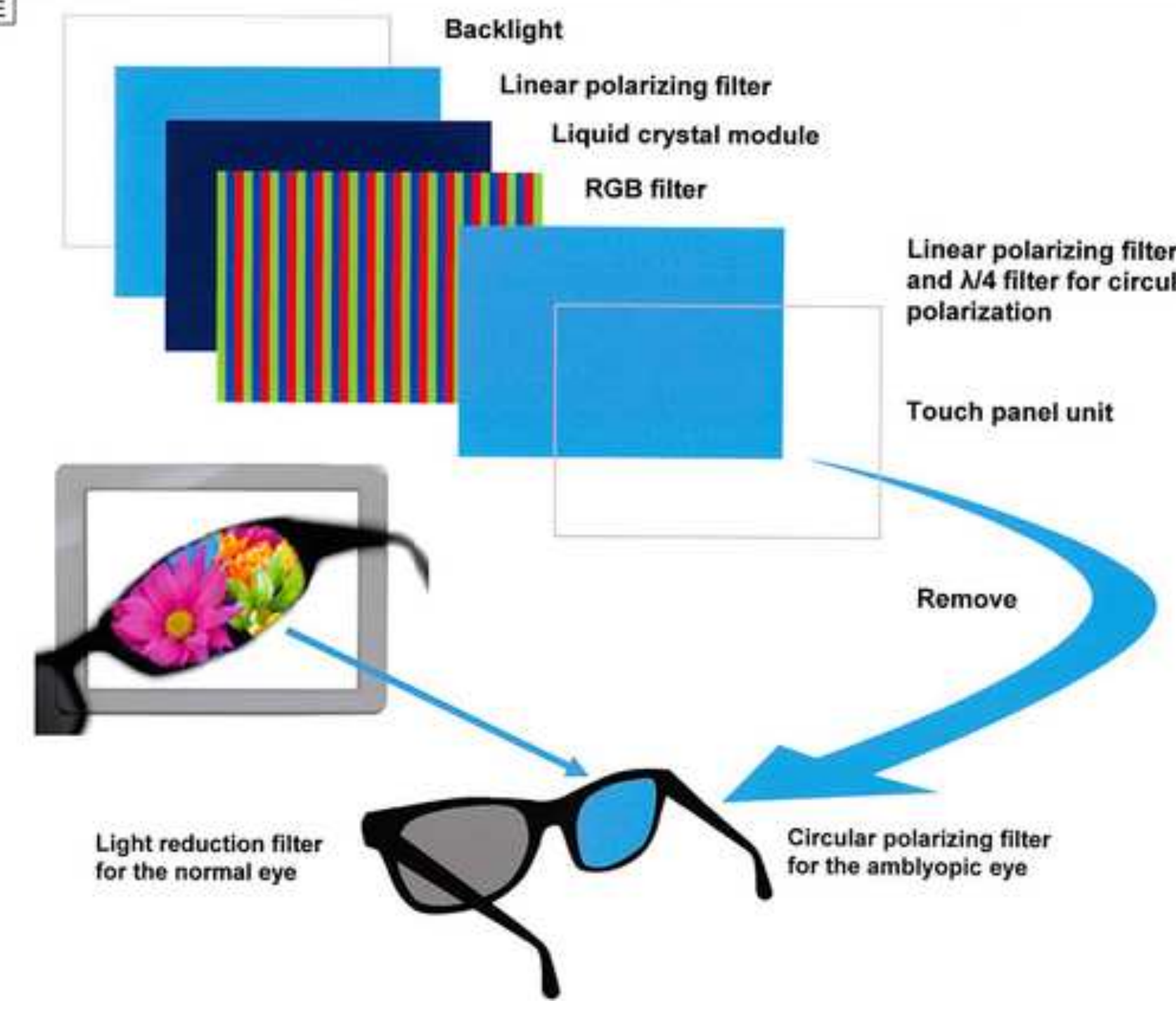

Linear polarizing filter and N/4 filter for circular

Touch panel unit 


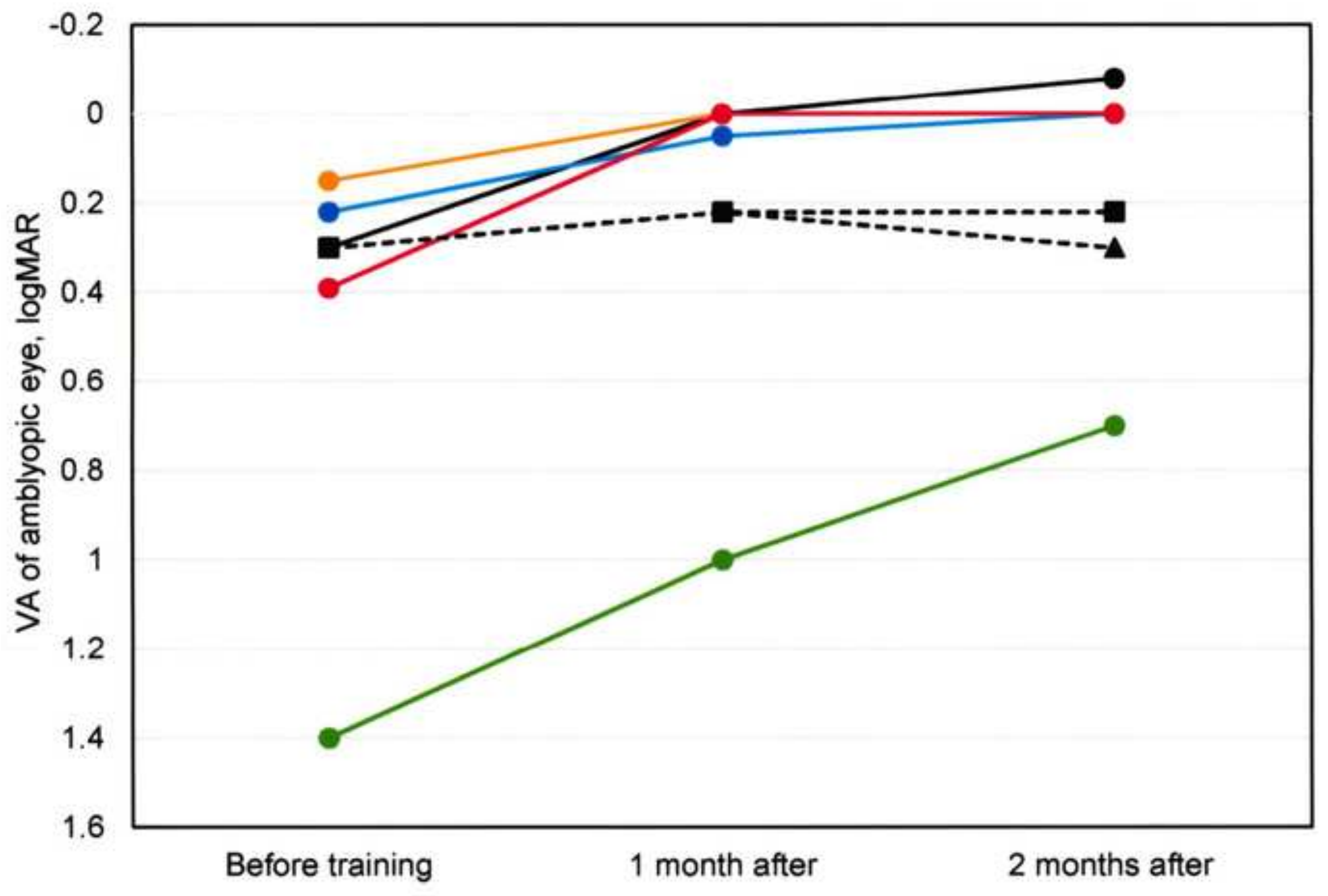

$\longrightarrow$ Child $1 \longrightarrow$ Child $2 \longrightarrow$ Child $3 \longrightarrow$ Child 4

$\longrightarrow$ Child $5 \quad$--D---Child 6 ---1--- Child 7 